\title{
On Crane's Psychologistic Account of Intentionality
}

\author{
Mohammad Saleh Zarepour ${ }^{1}$ (D)
}

Received: 21 March 2017 / Accepted: 30 January 2018 /Published online: 1 March 2018

(C) The Author(s) 2018. This article is an open access publication

\begin{abstract}
The intuition that we can think about non-existent objects seems to be in tension with philosophical concerns about the relationality of intentionality. Tim Crane's psychologism removes this tension by proposing a psychologistic account of intentionality according to which intentionality is a purely non-relational notion. I argue that his account has counterintuitive consequences regarding our thoughts about existing objects, and as such is insufficiently plausible to convince us to reject the relationality of intentionality.
\end{abstract}

Keywords Psychologism - Intentionality·Aboutness - Representation - Object of thought

Consider the following sentence:

(S) Sherlock Holmes is famous.

Many ordinary, non-philosopher speakers of the language have strong intuitions that can be expressed as follows:

Non-existence intuition (NI): Sherlock Holmes does not exist.

Aboutness intuition (AI): The thought expressed by (S) is about Sherlock Holmes.

More generally, ordinary speakers pretheoretically believe that there are thoughts about non-existents. However, given certain longstanding philosophical concerns, it is not an easy task to provide a plausible philosophical theory that confirms these intuitions. For many philosophers believe the following theses:

Mohammad Saleh Zarepour msz26@cam.ac.uk

1 Clare Hall, University of Cambridge, Cambridge CB3 9AL, UK 
Relationality of Intentionality (RI): Intentionality is a substantial relation between a thought (or the person who entertains it) and what the thought is about (i.e. the object of thought).

Sterility of Non-existence ( $S N)$ : Non-existence is sterile. Non-existents cannot bear substantial properties, nor stand in substantial relations. They cannot make any contribution in truth making.

However, the conjunction of (NI) and (AI) seems to be in tension with the conjunction of (RI) and (SN). According to (RI), every intentional phenomenon-e.g. representation or aboutness - is substantively relational. ${ }^{1}$ Given (SN), non-existents cannot stand in substantial relations. Such relations are instantiated only when their relata exist. Therefore, non-existents cannot be among the relata of a substantial relation. In particular, they cannot stand in the intentionality relation. Hence, non-existents cannot be represented, and our thoughts cannot genuinely be about them. In other words, if we endorse the relationality of intentionality (RI), the non-existence of Sherlock Holmes (NI) and the sterility of non-existence (SN), then we have to accept that the thought expressed by (S) is not about Sherlock Holmes; we should, therefore, reject (AI). This is what I call the Empty Aboutness Quadrilemma.

To escape from this quadrilemma, we must reject, at least, one of (NI), (AI), (RI) or (SN). Some philosophers reject (NI). Fictional realism is the most popular approach among the proponents of this option. According to fictional realism, fictional characters such as Sherlock Holmes do really exist, though not as concrete objects. Fictional characters are abstract objects which really exist, can accept properties and stand in relations. Therefore, Sherlock Holmes as an abstract object can, in principle, stand in a substantial relation such as intentionality. Consequently, we can think 'about' Sherlock Holmes.

Our second option in dealing with this quadrilemma is rejecting (SN). Adherents of this option are usually labeled 'Meinongians'. They believe that fictional characters do not really exist, but can still accept real properties, stand in substantial relations and contribute in truth making. Sherlock Holmes, Meinongians argue, is a non-existent object which can stand as the relatum of a substantial relation like intentionality. Therefore, although Sherlock Holmes does not exist, we can think about him.

Denying (AI) is the third option. Some philosophers believe that the thought expressed by $(\mathrm{S})$ is not genuinely about Sherlock Holmes. It is either about some existing entity (but not Sherlock Holmes, which does not exist) or about nothing at all. It is only an 'illusion,' therefore, that we can think about non-existents. ${ }^{2}$ Some advocates of this approach argue, for example, that (S) in fact expresses a descriptive thought or something which contains an implicit fictional operator such as 'according to the story ...' or the like. As a result, that thought is primarily about properties, fictions, mental representations, or some other thing which really exists, not about a non-existent. More specifically, descriptivists claim that whenever we seemingly have a representation of a non-existent, what we really have is a combination of some

\footnotetext{
${ }^{1}$ For a defense of the relational account of intentionality, see Stalnaker (1988, Ch. 1). Substantial relations should be understood in contrast to pleonastic relations as introduced by Schiffer (2003). I will shortly return to this distinction.

${ }^{2}$ Azzouni $(2014,2015)$ discusses how our minds create aboutness illusions.
} 
representations of existent properties. These representations are integrated and unified by, for example, an internal unifying cognitive mechanism in our mind and, consequently, we have an 'illusion' that a non-existent object is directly represented. Therefore, although it may seem that we have a singular representation of Sherlock Holmes as a non-existent object, what we really have is only a descriptive representation of some existent properties, e.g. being a detective, being smart, being addicted to cocaine, etc. The thought expressed by (S) is about these existing properties, not about a nonexistent object, i.e. Sherlock Holmes.

Our last option is to reject (RI). In a series of works, ${ }^{3}$ Tim Crane has proposed a psychologistic solution to the Empty Aboutness Quadrilemma by arguing that intentionality is not a substantial relation. Crane thus seeks to reject (RI) while preserving $(\mathrm{NI}),(\mathrm{AI})$, and $(\mathrm{SN}) .{ }^{4}$ His solution is based on introducing and defending a psychologistic account of intentionality that is entirely non-relational. $\mathrm{He}$ argues that intentionality is not a relation to its objects, because of the phenomenon of thought about the non-existent. ${ }^{5}$ In the sequel, I discuss this account.

According to Crane's psychologism, the most plausible explanations of fundamental mental phenomena can be given only by exploring psychological reality. One crucial constituent of Crane's psychologism is a purely non-relational account of intentionality according to which (a) all mental phenomena are intentional ${ }^{6}$; (b) every intentional state of the mind has an object which that state is about or directed on; (c) some intentional objects, i.e. objects of intentional states, exist and some do not and (d) intentionality is not a substantial relation. ${ }^{7}$ The psychologistic solution to the Empty Aboutness Quadrilemma is built on (c) and (d). Crane's understanding of the notion of aboutness is very liberal. He appeals to a 'loose' sense of aboutness which ordinary speakers of the language use in their everyday talk. In this sense our thoughts can be about non-existents as much as they can be about existents, since to be about something does not involve instantiation of a real relation. ${ }^{8}$ Intentionality is directedness on something. ${ }^{9}$ Sometimes our thoughts are directed on exiting things, sometimes on non-existing things. The fact that mind is directed on a thing does not entail that that thing exists. Our thoughts can therefore be about non-existents.

Crane elaborates his understanding of aboutness based on the notion of representation, which for him is a basic and indefinable notion. ${ }^{10}$ Having a representation of something is sufficient for thinking about it. In entertaining the thought expressed by (S) we have a representation of Sherlock Holmes and it guarantees

\footnotetext{
${ }^{3}$ See Crane (2001, 2013) and essays reprinted in his (2014).

${ }^{4}$ Azzouni (2014) and Casati and Fujikawa (2016) have shown, in my view convincingly, that Crane's psychologism entails some sort of Meinongianism. However, I do not intend to discuss this issue here. My aim is to discuss his non-relational account of intentionality.

${ }^{5}$ Crane (2013, ix)

6 This view, which is usually called 'intentionalism', is extensively defended in Crane (2001) and Crane (2014, Essays 5 \& 8).

${ }^{7}$ For (b) and (c) see Crane (2013, 4-5) and for (d) see Crane (2013, 9 \& 66).

${ }^{8}$ Crane $(2013,7-11)$

${ }^{9}$ Crane (2014, Essay 5, 94-95)

${ }^{10}$ Crane $(2013,115-117)$
} 
that our thought is about Sherlock Holmes. Aboutness is not, therefore, a real or substantial relation. Crane says:

I do not assume that simply because ' $x$ is about $y$ ' is a two-place predication, it expresses a real relation: I distinguish between the adicity of a predication, and the reality it talks about. Intentionality or aboutness is typically described in terms of a twoplace predication; but I want to distinguish this idea from the idea of a real relation. ${ }^{11}$

Real or substantial properties and relations should be understood in contrast to pleonastic properties and relations in Schiffer's sense. ${ }^{12}$ Substantial entities can contribute in making some truths. Pleonastic properties, by contrast, are themselves truthbased. ${ }^{13}$ They do not really exist and cannot genuinely contribute in making something true. We accept pleonastic entities by accepting some inferences from certain truths, without any ontological commitment to these entities. ${ }^{14}$ Pleonastic entities therefore depend on truths, and truths themselves depend on substantial entities. Whiteness, for example, is a substantial property which can contribute to making some truths. My laptop's having the property of whiteness is the truth-maker of the sentence 'my laptop is white.' Being taller than somebody is, similarly, a substantial relation whose instantiation by, respectively, Usain Bolt and Lionel Messi makes 'Bolt is taller than Messi' true. Intentionality or aboutness, on the other hand, is a non-substantial pleonastic relation. From the truth of (AI), we can infer that there is a pleonastic relation of aboutness between (S), or the thought expressed by it, and Sherlock Holmes. But the truth of (AI) does not itself depend on the instantiation of this aboutness relation. Sherlock Holmes does not exist in any sense and cannot stand in any real relation. The truth of (AI) depends on this fact, that the thought expressed by $(\mathrm{S})$ contains a representation of Sherlock Holmes. Representations really exist and can contribute in making some truths. Having a representation of something can make it true that we have a thought about that thing.

Crane believes that reference, contrary to aboutness, is a substantial relation which cannot be instantiated in the absence of (at least one of) its relata. He says:

'Aboutness' is the mere representation of something in words or thoughts, whether or not it exists. So although my word 'Pegasus' does not refer to the mythological winged horse Pegasus - 'Pegasus' is, after all, commonly called a 'non-referring term' - I can talk or think about Pegasus. ${ }^{15}$

Therefore, non-existent objects, according to psychologism, are pleonastic intentional objects to which we cannot refer. However, it is possible to think about them. The key element of the psychologistic solution to the Empty Aboutness Quadrilemma is rejecting the relationality of intentionality and explaining the notion of aboutness based on the basic notion of representation.

\footnotetext{
${ }^{11}$ Crane $(2013,9)$

12 Schiffer (2003)

${ }^{13}$ I borrow this terminology from Azzouni (2013, 357, n. 31). His distinction between object-based and truthbased properties is equivalent to Crane's distinction between substantial and pleonastic properties, or so it seems to me.

${ }^{14}$ Crane (2013, Sec. 3.4)

${ }^{15}$ Crane $(2013,9)$. His emphasis
} 
Crane's project involves many insightful ideas, but, as I will show, it is unsuccessful in solving the Empty Aboutness Quadrilemma. ${ }^{16}$ The psychologistic solution is based on a misleading understanding of the notion of aboutness which renders some intuitively distinct thoughts about different existing things as being about the same thing. In other words, to preserve the possibility of empty aboutness, he sacrifices some of our intuitions about non-empty aboutness, or so I will argue.

Suppose that through the window of my flat, in a specific situation and at a particular time of day, I see John walking in the street. Based on this perceptual experience, some thoughts about the object of my experience appear in my mind. But, unfortunately, at the end of that day I forget anything happened and any thought I had. Suppose moreover that the day after I have exactly the same experiences and thoughts, this time of Jones, John's twin who looks like him in all respects. At the same time of day and in the same situation, through the same window of my flat, I see Jones walking in the same area. Based on this perceptual experience, similar thoughts about the object of my experience appear in my mind. Finally, like the first day, at the end of the second day I forget everything happened and any thought I had on that day. In other words, from my subjective point of view there is no difference between these two days. By assumption, before these days I have never seen John and Jones and I do not know that they are twins. Now, it seems intuitively undeniable that the thoughts I have about the object of my experiences on these two days are about distinct things, although unbeknownst to me. My first-day thoughts are about John, while my second-day thoughts are about Jones. But, given Crane's psychological account of intentionality, we have to accept that my thoughts on these two days are about the same thing. Generally, if aboutness is not instantiation of a substantial relation, then thoughts with similar non-relational features should have the same aboutness; they should be about the same object. It is a consequence of Crane's psychologism that a person's internally or subjectively indistinguishable mental states (or thoughts), which have the same phenomenology and the same function in the person's internal or subjective life, have the same object. ${ }^{17}$ However, the above scenario about John and Jones clarifies that it is in principle possible for subjectively indistinguishable mental states (or thoughts) to be about different things through being related to distinct existents. ${ }^{18}$

Crane holds that intentionality is a purely non-relational notion. Moreover, he endorses, 'along with the philosophical orthodoxy, that if a condition or property is not relational then it is intrinsic.' Accordingly, he believes that intentionality 'must be an intrinsic feature

\footnotetext{
${ }^{16}$ For some criticisms of Crane's project, see Azzouni (2014), Spinelli (2016), and Casati and Fujikawa (2016).

${ }^{17}$ I use the terms 'subjective' and 'subjectively' interchangeably with the terms 'internal' and 'internally', respectively.

${ }^{18}$ Crane $(2013,159)$ seem to believe, correctly in my view, that intentionality of a person's thought can somehow depend not only on the phenomenological features of the thought but also on its internal connections (e.g. causal or dispositional connections) to other internal elements of the person's mind (i.e. her other thoughts or mental states). More precisely, he admits that thoughts with different internal connections have different internal functions, play different roles in their subject's mental life, and can in principle be about different things. However, this does not save Crane's psychologism from my objection. In the above scenario about John and Jones, from my internal point of view, there is no difference between my experiences and thoughts on those two days. There is no internal factor, either phenomenological or functional, based on which my thoughts on those two days can be distinguished from each other. My thoughts on those two days have the same phenomenology and similar internal connections and functions. They are subjectively indistinguishable but about different existents. This is what refutes Crane's psychologistic account of intentionality.
} 
of mental states or acts. ${ }^{19}$ It does not mean, however, that a thought (or a person who entertains it) can never be in a substantial relation to the object of the thought. When someone thinks about an existent, she might be in many different substantial relations (e.g. causation, sisterhood, being taller than, etc.) to the object of her thought. But it cannot be, even partially, in virtue of those relations that her thought is about its object. Otherwise, aboutness is, at least partially, relational (not purely non-relational). ${ }^{20}$ But if aboutness is an intrinsic feature of mental states, then intrinsically indistinguishable mental states should be about the same thing.

Put otherwise, according to psychologism, X's thinking about Y does not depend on the existence of Y. Consequently, it does not depend on the instantiation of any substantial relation between X (or her thought) and Y. It merely depends on the internal aspects of X's mind. As Crane explicitly puts forward, 'whether or not (V) [i.e. the sentence "Le Verrier is thinking about Vulcan"] is true ought to depend on what is going on in Le Verrier' s mind, not on the mere fact that 'Vulcan' does not refer. ${ }^{21}$ It means that aboutness of a person's thought is determined by merely internal aspects of her mind. So friends of psychologism should embrace that subjectively indistinguishable thoughts are about the same thing. As a result, my thoughts on those two days, in the above scenario, should be understood as being about the same thing.

The more peculiar consequence we have to endorse, if we accept Crane's theory, is that my thoughts on these two distinct days refer to different things but are about the same thing. Reference is a relational notion. Therefore, instantiation of a real relation, whatever its nature is, determines what my thought refers to. Put otherwise, what makes it the case that my thought refers to a certain object is instantiation of a specific relation I have (or my thought has) with that object. My first-day thought refers to John because John is the relatum of that relation on the first day. By contrast, Jones is the relatum of the reference relation on the second day and, therefore, my second-day thought refers to Jones. Aboutness, on the other hand, is purely non-relational. What makes it the case that my thought is about a certain object is not instantiation of a real relation; as I showed, it is only purely internal aspects of my thought. But as we see in this example, some sort of underdetermination about aboutness is entailed if we rely merely on purely non-relational and internal aspects of the mind. We can easily imagine situations in which the same phenomenological state of the mind with the same internal connections to other states is associated with different relations to the external world. Distinct objects can be represented similarly. More generally, the same non-relational aspects of the mind can be associated with different relational aspects. According to psychologism, the aboutness of a thought is determined by merely non-relational aspects of the mind, but its referent is determined by instantiation of a real relation to an existing object. Consequently, it should not be unexpected that we can have thoughts with the same aboutness but different reference.

There is still another issue, which is perhaps even more controversial. As I showed in the above thought experiment, if we accept that aboutness of our thoughts should be

\footnotetext{
${ }^{19}$ Crane (2014, Essay 10, 206).

${ }^{20}$ Crane does not believe that intentionality is a mixture of some relational and some non-relational aspects of the mind.

${ }^{21}$ Crane $(2013,55)$. Indeed, if we believe, as Crane seemingly does, that it is in principle possible to determine the truth value of $(\mathrm{V})$ before knowing anything about the existence of Vulcan, then we should accept that the aboutness of Le Verrier's thoughts merely depend on the internal aspect of his mind.
} 
determined by purely non-relational aspects of the mind, then my thoughts on those two days are about the same thing. But which thing? Even if we admit this odd consequence, it is still unclear what my thoughts are about. The story is somehow symmetric with respect to John and Jones. ${ }^{22}$ Therefore, choosing one of them randomly and claiming that my thoughts on both of those two days are about that randomly selected person (not the other) seems implausible. On the other hand, my thoughts on these days cannot be about both of the two brothers. Having a mental representation that is subjectively indistinguishable from a representation of $x$ is not sufficient for having a thought about $x$. If it was, my thoughts about my laptop would be about any other thing with similar phenomenological aspects, e.g. all other laptops the same model and color as mine. Finally, it is counterintuitive to say that my thoughts are about the mental representation itself. Thinking about an object in the external world is, in my view, sharply distinct from thinking about a mental representation. In brief, even if we accept that my thoughts on those two days are about the same object, we do not know what that object is.

Obviously, proponents of psychologism would be not happy with these counterintuitive consequences. But it is not an easy task to provide psychologism with the tools for blocking such consequences without rejecting some of its core elements, or so I will argue.

One might say that my thoughts on these two days are about two distinct objects, because I have two different representations on those days. The representation I have on the first day is of John, while on the second day I have a representation of Jones. Now, if we understand thinking about $x$ as having a representation of $x$, then we should conclude that my first-day thoughts are about John, while my second-day thoughts are about Jones. This reply is, however, an untenable verbal maneuver. Representation is itself either relational or non-relational. If it is non-relational (i.e. if having a representation is not an instantiation of a real relation), then we have a similar underdetermination problem about the of-ness of representations. Crane himself believes that 'representation does not seem to be a relation in any straightforward sense, since we can represent things that do not exist. ${ }^{23}$ But if the of-ness of representations is to be determined based only on non-relational or internal aspects, then the representation I have on the first day is a representation of John as much as it is a representation of Jones. If, on the other hand, representation is a relational notion and the of-ness of representations is determined only by the instantiation of a substantial relation, then aboutness will be a relational notion too. In this case, having a thought about $x$ is tantamount to having a representation of $x$. But having a representation of $x$ is itself tantamount to having a substantial relation to $x$. Therefore, it seems reasonable to conclude that having a thought about $x$ is tantamount to having a substantial relation to $x$. The moral is that this strategy cannot save psychologism from my objection.

Crane says that 'when we form a representation of some object, we 'open a file' on that object. We then come to store certain information in the file'. ${ }^{24}$ He believes that what makes a file a general one is 'not that as a matter of fact the information is true of many things, but the fact that a thinker can make sense of it being true of many things, taken one

\footnotetext{
${ }^{22}$ We can simply ignore the order of the days on which I have seen John and Jones. According to the story, at the end of each day I forget everything that happened on that day. Therefore it is not problematic to suppose that the story is symmetric with respect to John and Jones. This ensures us that, from my internal point of view, my thoughts on those two days look similar to each other in all internal respects.

${ }^{23}$ Crane $(2013,117)$

${ }^{24}$ Crane $(2013,158)$
} 
by one (or of different things in different possible situations). ${ }^{25}$ Now, one might argue, on behalf of Crane, that the subject of subjectively indistinguishable thoughts can make sense of each of those thoughts being true of many things, taken one by one. Therefore, my thoughts on those two days, though seeming singular thoughts each of which about a specific person, are indeed general thoughts about both John and Jones. ${ }^{26}$

However, this maneuver cannot solve the problem. I cannot make sense of my secondday thoughts being true of anybody except Jones who I see through the window of my flat on the second day. I cannot make sense of seeing a person being seeing another one. Seeing Jones on the second day puts me in a specific relation to him because of which my second-day thoughts are about him, rather than John. But, if we deny that aboutness is instantiation of a relation, then being related to Jones cannot prevent my second-day thoughts to be also about John. The main problem is that psychologism mistakenly pushes us to accept subjectively indistinguishable singular thoughts about different objects as identical general thoughts which can be simultaneously about many different things.

Another possible way out might be to endorse a pluralist account of intentionality according to which although intentionality is non-relational in empty discourse, it is substantively relational in non-empty discourse. According to this pluralist approach, therefore, there is some sort of ambiguity in the use of the notion of aboutness in ordinary everyday talk. When we are thinking and talking about an existing object, the instantiation of a substantial relation with that object is what makes it the case that our thought is about that specific object. Otherwise, when we are thinking about a nonexisting object, the merely internal aspect of that episode of thinking is what makes it the case that our thought is about that specific non-existent object. ${ }^{27}$

However, this solution seems somehow ad hoc, at least until a persuasive independent justification is provided for drawing such a distinction between empty and nonempty discourse. Crane himself, for exactly the same reason, clearly rejects the pluralist account of intentionality:

Searle tries to get around this by detecting an ambiguity between 'intensional' and 'extensional' senses of 'about'. But this does not help, for it is really just another way of saying that for some substitutions for $\mathrm{X}$ and $\mathrm{Y}$, ' $\mathrm{X}$ is thinking about $\mathrm{Y}$ ' does not imply that Y exists; and this is something we already knew. Since we have no other way of detecting this ambiguity in 'about', we should be suspicious of its existence. ${ }^{28}$

Crane should therefore seek another means to solve the objection. The most plausible strategy he could follow is, in my view, to appeal to what I call a 'functionalist interpretation' of aboutness. In the literature on mental content, some internalists have introduced 'narrow content' as a function from contexts to 'broad contents' ${ }^{29}$ Crane could say, analogously, that aboutness is a function from contexts to what our thoughts refer to. It is not itself a substantial relation, but it sheds light on the substantial reference relations we have (if any). ${ }^{30}$ The aboutness function determines what our

\footnotetext{
$\overline{25}$ Crane $(2013,159)$. His emphasis.

${ }^{26}$ Thanks to an anonymous reviewer who proposed this objection.

${ }^{27}$ For a good defense of a pluralist account of aboutness, see Azzouni (2010 \& 2012).

${ }^{28}$ Crane $(2013,96)$

${ }^{29}$ Fodor (1987)

${ }^{30}$ Crane (2001, Ch. 4, Sec. 36, 117-121) seems to be sympathetic to this formulation of aboutness.
} 
thought is about, but it does not determine whether or not it (i.e., what our thought is about) exists. This function characterizes those internal and phenomenological aspects that the referent of a thought would impose on our mind, albeit if the thought had a referent. However, the aboutness function does not, and cannot indeed, say if our thought really refers to something in the external world. The thought expressed by (S), for example, is about Sherlock Holmes, whether or not he exists (see the latter quote again).

I am not optimistic that this strategy can rescue Crane's psychologism. If we interpret narrow content as a function from contexts to broad contents, then we are accepting the possibility of having a similar narrow content with different broad contents in different contexts. Similarly, if we accept the functionalist account of aboutness, then we have to accept that it is possible to have thoughts with similar aboutness functions but different referents. In other words, it is possible to have thoughts that are about the same thing but refer to different things. The undesired consequence will return. Consider the previous example of John and his twin, Jones. Do my thoughts on those two days have the same aboutness function? If Crane answers this question positively, then he should accept that my thoughts on the two days, while referring to two distinct objects, are about the same thing. That is obviously counterintuitive. At least, this interpretation of the notion of aboutness is not what ordinary use of the term 'about' suggests. If he says, on the other hand, that I have two distinct aboutness functions on these two days, then he owes us an explanation of what makes these functions different from each other. If these functions are identified by merely non-relational, internal and phenomenological aspects of mind, then it seems that they are identical, because I am in the same internal state on these two days. If, on the other hand, these functions are identified under the influence of some external factors, then aboutness is, at the end of the day, genuinely relational. A substantial relation with those external factors determines what the aboutness function of my thought is and what my thought is about.

It is time to conclude. I proposed a problem for Crane's non-relational account of intentionality. Then I discussed and consequently rejected the most plausible options he might have to respond my objection without giving up some of the principal elements of his psychologism. I conclude that Crane's psychologism, at least in its current form, cannot convince us that aboutness is a non-relational notion. It is true that relationality of intentionality, as the Empty Aboutness Quadrilemma reveals, is in tension with some of our ordinary empty aboutness intuitions. But the non-relationality of intentionality seems to be too expensive a solution. It contradicts our intuitions about non-empty aboutness. The psychologistic account of intentionality renders some thoughts that are intuitively about distinct existing objects as being about the same thing. This is, in my view, a grave consequence.

I showed that the relationality and non-relationality of intentionality contradicts, respectively, the empty and non-empty aboutness intuitions. Now, if we do not want to espouse a plurality account of intentionality, and feel obliged to accept one of these horns, then the relational account of intentionality is preferable. This conclusion is undeniable for, at least, everybody who believes, like me, that compared to our intuitions about non-empty discourse, our intuitions about empty discourse are more likely to be mistaken. 
Acknowledgement For extremely helpful comments and/or discussions, I am thankful to Jody Azzouni, Seyed N. Mousavian, and an anonymous reviewer of this journal.

Open Access This article is distributed under the terms of the Creative Commons Attribution 4.0 International License (http://creativecommons.org/licenses/by/4.0/), which permits unrestricted use, distribution, and reproduction in any medium, provided you give appropriate credit to the original author(s) and the source, provide a link to the Creative Commons license, and indicate if changes were made.

\section{References}

Azzouni, J. (2010). Talking about nothing: numbers, hallucinations, and fictions. Oxford: Oxford University Press. Azzouni, J. (2012). Referring to what is and to what isn't. In W. P. Kabasenche, M. O'Rourke, \& M. H. Slater (Eds.), Reference and referring (pp. 253-269). Cambridge: MIT Press.

Azzouni, J. (2013). Hobnobbing with the nonexistent. Inquiry: An Interdisciplinary Journal of Philosophy, 56(4), 340-358.

Azzouni, J. (2014). Freeing talk of nothing from the cognitive illusion of aboutness. The Monist, 97(4), 443-459.

Azzouni, J. (2015). Mathematical fictions. In A. C. Sukla (Ed.), Fiction and art: explorations in contemporary theory (pp. 63-77). London: Bloomsbury Academic.

Casati, F., \& Fujikawa, N. (2016). Nonexistent objects as truth-makers: against Crane's reductionism. Philosophia, 44(2), 423-434.

Crane, T. (2001). Elements of mind: an introduction to the philosophy of mind. Oxford: Oxford University Press. Crane, T. (2013). The objects of thought. Oxford: Oxford University Press.

Crane, T. (2014). Aspects of Psychologysm. Oxford: Oxford University Press.

Fodor, J. (1987). Psychosemantics: the problem of meaning in the philosophy of mind. Cambridge: MIT Press. Schiffer, S. (2003). The things we mean. Oxford: Oxford University Press.

Spinelli, N. (2016). What it is to be an intentional object. Disputatio, 42, 93-112.

Stalnaker, R. C. (1988). Inquiry. Cambridge, MA: MIT Press. 